\section{Comment}

Ten per cent of the mentally impaired adults we studied suffered from recurrent vomiting. No common aetiological factor could be found to explain the high prevalence of oesophageal and upper gastrointestinal disorders in this group. Posture may be one important factor ${ }^{3}$; most patients spend their day and night semirecumbent, even when eating. In some patients spasticity of the abdominal muscles may exacerbate reflux through abdominal compression. ${ }^{4}$ In addition, many of the patients were taking drugs that reduce the pressure of the lower oesophageal sphincter. In children hypoxic damage to the vagal nuclei at birth has been suggested as a cause of gastro-oesophageal reflux, and this could be the cause in adult patients. ${ }^{2}$

Adults who are mentally impaired may not be able to indicate that they have dyspeptic symptoms associated with reflux. Vomiting may therefore be the first sign of serious oesophageal disease. Ideally all such patients should be investigated, but the difficulties entailed in even simple examinations make this a counsel of perfection. Empirical treatment with antacids and other antireflux measures may be most appropriate for patients in whom investigation is thought inappropriate.

We thank Dr S Hadi and Dr S Munchi for their invaluable help and for allowing us to study their patients; our colleagues who treated the patients; and Mrs S M Alcock for her help in preparing the manuscript.

1 Byrne WJ, Campbell M, Asheraft E, Seibert JJ, Evler AR. A diagnostic approach to vomiting in severely retarded patients. Am $\mathcal{J}$ Dis Child 1983;137:259-62.

2 Sondhelmer JM, Morris BA. Gastroesophageal reflux among severely retarded children. F Pediatr 1979;94:710-4

3 Wesley JR, Wran AG, Saraham TM, Kleing MD, White SJ. The need for evaluation of gastroesophageal reflux in brain damaged children referred for evaluation of gastroesophageal reflux in brain damaged
feeding gastrostomy. Am $\mathcal{F}$ Pediatr Surg 1981;16:866-71.

4 Kassem NJ, Groen JJ, Grankel M. Spinal deformaties and oesophageal hiatus hernia. Lancet 1965;i:887-9.

(Accepted 14 April 1989)

\title{
Defibrillation by ambulance staff who have had extended training
}

\author{
D Wright, C James, A K Marsden, \\ A F Mackintosh
}

St James's University

Hospital, Leeds LS9 7TF

D Wright, MRCP, cardiology registrar

A F Mackintosh, FRCP, consultant cardiologist

\section{West Yorkshire}

Metropolitan Ambulance

Authority, Birkenshaw,

Bradford

C James, assistant chief

metropolitan ambulance officer

Pinderfields Hospital, Wakefield

A K Marsden FRCs, consultant in accident and emergency

Correspondence to:

Dr Mackintosh.

Br Med f 1989;299:96-7
With mounting evidence of the efficacy of defibrillation by paramedical staff outside hospital ${ }^{12}$ a national scheme for extended training in ambulance aid was introduced in $1986 .{ }^{3}$ Experienced ambulance staff receive training in emergency care, including defibrillation, management of airways, and intravenous replacement of fluids. Adoption of the scheme and deployment of trained staff are left to the individual ambulance authorities.

We report the results of defibrillation by staff who had extended training in West Yorkshire during 1987.

\section{Patients, methods, and results}

Each extended trained member of the ambulance staff was dispatched in a rapid response unit: a car with full resuscitation equipment. For each call a standard report form was completed, and these forms provided the data for this report. During the year the number of units increased from three to five and the number of trained ambulance staff from nine to 24 . Only five of the nine health districts within West Yorkshire were covered, one unit being provided for each district during the day and evening. One district had a programme for training the general public in resuscitation. For this report resuscitation by a bystander indicated some attempt at resuscitation before the trained ambulance staff arrived. Response time was the time from receiving the call to arriving at the scene plus one minute for processing by ambulance control. Results were analysed by $\chi^{2}$ test with Yates's correction for continuity for small numbers.

In the 12 months the units attempted defibrillation on 110 patients ( 85 men; age range $36-89$ ). Ventricular fibrillation had occurred in all patients but was not the initial rhythm disturbance in 26 . The table shows the results. Seventeen patients survived to leave hospital ( $15 \%$ survival overall, $20 \%$ survival among cases with initial fibrillation).

No survivor had pronounced neurological defects, though one patient with a severe defect died in hospital three weeks after admission. Eleven survivors were intubated by the ambulance staff, and drugs (lignocaine, adrenaline, or atropine) were used in nine. Detailed information was missing on four patients who died. For the patients who had a cardiac arrest before the unit arrived a short response time significantly improved the outcome $(p<0.01)$. The maximum response time for a survivor was 11 minutes. Attempts at resuscitation by bystanders and the arrest occurring in public also improved the outcome but not significantly.

\section{Comment}

These results show the initial potential of the NHS scheme without a large resuscitation training programme for the public. Extended trained ambulance staff can not only deal with ventricular fibrillation in transit but also successfully treat patients who have developed this arrhythmia before their arrival. Although the rate of success is similar to that in other reports, ${ }^{24}$ the number of survivors was not large. The units attended only a minority of the episodes of ventricular fibrillation outside hospital in West Yorkshire. Prolonged resuscitation may be required, and the other skills taught in extended training, particularly intubation, might be important.

Results of defibrillation by ambulance staff who had had extending training in 110 patients

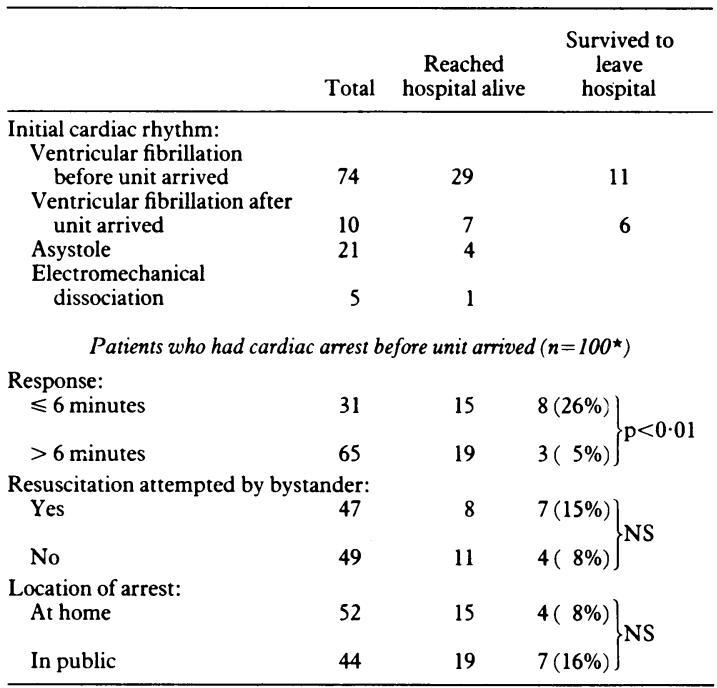

^Records incomplete for four patients. 
We confirm the importance of short response times, and they should be reduced further when more staff are available. About half of the patients received some resuscitation from bystanders despite a shortage of formal training of the public.

Without the availability of rapid defibrillation resuscitation by bystanders will be only of limited value. The introduction of semiautomatic, advisory defibrillators for non-extended trained crews should reduce the time to defibrillation and make this procedure available to more people. ${ }^{5}$ This combination of extended and non-extended trained crews may prove most effective.

This study was made possible by the work of many members of the ambulance service and the extended training advisory group.

1 Mackintosh AF, Crabb ME, Grainger R, Williams JH, Chamberlain DA. The Brighton resuscitation ambulances: review of 40 consecutive survivors of outof-hospital cardiac arrest. $\mathrm{Br} \mathrm{Med} \mathcal{F} 1978$;i:1115-8.

2 Eisenberg MS, Copass MK, Hallstrom AP, et al. Treatment of out-of-hospital cardiac arrests with rapid defibrillation by emergency medical technicians. $N$ Engl f Med 1980;302:1379-83.

3 Ambulance Staff Training Committee. Extended training in ambulance aid. Bristol: NHS Training Authority, 1987.

4 Weaver WD, Cobb LA, Hallstrom AP, Fahrenbruch C, Copass MK, Ray R. Factors influencing survival after out-of-hospital cardiac arrest. $\mathcal{J}$ Am Coll Cardiol 1986;7:752-7.

5 Weaver WD, Copass MK, Hill DL, Fahrenbruch C, Hallstrom AP, Cobb LA Cardiac arrest treated with a new automatic external defibrillator by out-of hospital first responders. Am $\mathcal{F}$ Cardiol 1986;57:1017-21.

(Accepted 7 April 1989)

\section{Cost minimisation study of transdermal glyceryl trinitrate in reducing failures of peripheral intravenous infusion}

\section{H T Khawaja, B J O’Brien, M J Buxton, PC Weaver}

Department of Surgery, St Mary's Hospital,

Portsmouth PO3 6AD

H T Khawaja, FRCS, research fellow

PC Weaver, FRCS, consultant surgeon

\section{Health Economics Research Group, Brune \\ University, Uxbridge Middlesex UB8 3PH \\ B J O'Brien, MSC, research fellow \\ M J Buxton, BA, senior research fellow}

Correspondence to: $\mathrm{Mr}$ Khawaja.

BrMed f 1989;299:97

Expected costs of using glyceryl trinitrate patches to delay failure of peripheral intravenous infusion
Phlebitis and extravasation are common causes of failure of peripheral intravenous infusion. ${ }^{12}$ Such failures result in discomfort to patients and reinfusion not only incurs extra costs but takes up staff time. Recent clinical trials showed that prophylactic use of transdermal glyceryl trinitrate reduced the incidence of phlebitis and infusion failure. ${ }^{3+}$ We assessed the effect on hospital resources when this method was used.

\section{Methods and results}

Data were obtained from an earlier trial on 340 consecutive patients requiring infusions in a general surgical ward. The patients were randomised to treatment with a self adhesive glyceryl trinitrate patch or an identical placebo patch; the patches for both groups were changed daily. The earlier study showed that using glyceryl trinitrate patches delayed failure of the infusion from 74 hours in the control group to 127 hours. ${ }^{4}$

Our evaluation used the method of cost minimisation $^{5}$ and assessed the net impact that patch treatment had on hospital resources. The expected cost of an infusion to time $t$ was the sum of the initial cost, the cost of changing the patch daily, and the cost of reinfusion weighted by the cumulative probability of failure to time t. We calculated the expected costs for the treatment and control groups. The costs of patches, cannulas, giving sets, and infusion fluids were taken as the prices that the hospital paid, net of discount. The

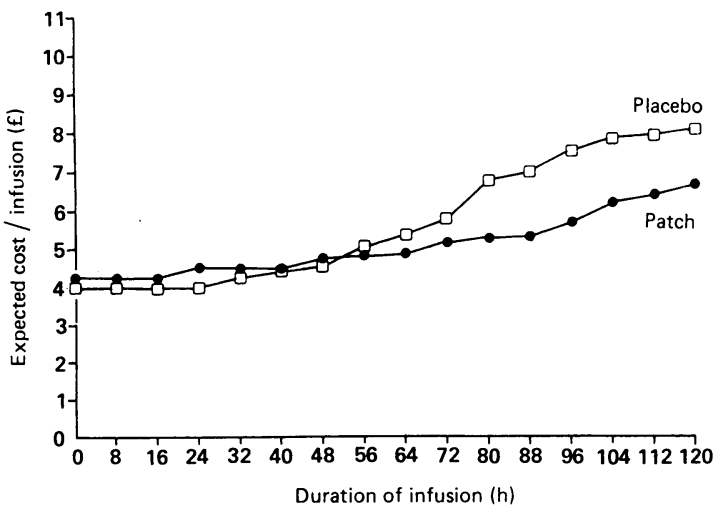

medical and nursing time entailed was estimated from a prospective sample of infusions in a general surgical ward. All costs were at $1987-8$ prices.

The costs were: $\mathrm{C}_{1}=$ cost of first infusion in patients with glyceryl trinitrate patch $=£ 4.27 ; \mathrm{C}_{2}=$ cost of first infusion in patients with placebo patch $=£ 4.00 ; \mathrm{C}_{3}=$ cost of reinfusion (glyceryl trinitrate patch) $=£ 4.51$; $\mathrm{C}_{4}=$ cost of reinfusion $($ placebo patch $)=£ 4.24 ; \mathrm{C}_{5}(\mathrm{t})=$ cost of changing glyceryl trinitrate patch daily (at $27 p$ per patch); $\mathrm{p}_{\mathrm{t}}, \mathrm{q}_{\mathrm{t}}=$ probability of failure of infusion at time $t$ (in treated $(p)$ and control (q) patients), where $0 \leqslant \mathrm{p}_{\mathrm{t}}, \mathrm{q}_{\mathrm{t}} \leqslant 1$.

The cost of reinfusion exceeded that of the first infusion because it included the time taken to dispose of used materials. The expected cost per infusion to time $t$ was therefore $\mathrm{C}_{1}+\mathrm{C}_{5}(\mathrm{t})+\mathrm{p}_{\mathrm{t}} \mathrm{C}_{3}$ in the treatment group and $\mathrm{C}_{2}+\mathrm{q}_{\mathrm{t}} \mathrm{C}_{4}$ in the control group.

For short term infusions ( 24 hours) the expected cost per infusion in the treatment group (£4.54) exceeded that in the control group $(£ 4.03)$ because the early rate of failure was small. For longer infusions (for example, 96 hours), however, the expected cost was lower in the treatment group ( $£ 5.77 v £ 7.60$ ). The cost was equivalent in the treatment and control groups at 48 hours (figure).

\section{Comment}

We found that the net impact on hospital resources of using glyceryl trinitrate patches depended on the duration of the infusion. Using the patches with infusions lasting longer than 48 hours was likely to generate savings; thus the patches should be considered when the infusion time is likely to exceed this threshold. For every 1000 infusions in place for 96 hours the total savings from using the patches would be $£ 1830$. Of this, $£ 950$ is the value of staff time released for other purposes and $£ 880$ the savings on consumables such as cannulas and infusion fluids after allowing for the cost of the patches.

Further studies that explore the benefits to patients of avoiding sequential infusion failure and analyse the costs that are incurred ${ }^{5}$ would be valuable.

\footnotetext{
We thank Ciba-Geigy Pharmaceuticals for supporting this study.

1 Arnold RE, Elliott EK, Holmes BH. The importance of frequent examination of infusion sites in preventing postinfusion phlebitis. Surg Gynecol Obstet of infusion sites

Thomas ET, Evers W, Racz GB. Postinfusion phlebitis. Anesth Analg 1970;49:150-9.

3 Wright A, Hecker JF, Lavis GBH. Use of transdermal glyceryl trinitrate to reduce failure of intravenous infusion due to phlebitis and extravasation. Lancet 1985;ii:1148-50

4 Khawaja HT, Campbell MJ, Weaver PC. Effect of transdermal glyceryl trinitrate on the survival of peripheral intravenous infusions: a double-blind prospective clinical study. Br F Surg 1988;75:1212-5.

5 Drummond MF, Stoddart GL, Torrance GW. Methods for the economic evaluation of health care programmes. Oxford: Oxford University Press, 1987.

(Accepted 29 March 1989)
} 